\title{
IdeAs
}

Idées d'Amériques

$18 \mid 2021$

Frontières dans les Amériques - Intégration, sécurité et migrations

\section{Fronteiras nas Américas - Integração, segurança e migrações: abordagens críticas}

Pierre-Alexandre Beylier, Anne-Laure Amilhat-Szary, Gregory Benedetti e Éric Tabuteau

Tradutor: Isabel Moraes

\section{OpenEdition}

\section{Journals}

\section{Edição electrónica}

URL: https://journals.openedition.org/ideas/12007

DOI: $10.4000 /$ ideas. 12007

ISSN: 1950-5701

\section{Editora}

Institut des Amériques

\section{Refêrencia eletrónica}

Pierre-Alexandre Beylier, Anne-Laure Amilhat-Szary, Gregory Benedetti e Éric Tabuteau, «Fronteiras nas Américas - Integração, segurança e migrações: abordagens críticas», IdeAs [Online], 18 | 2021, posto online no dia 01 outubro 2021, consultado o 16 novembro 2021. URL: http:// journals.openedition.org/ideas/12007 ; DOI: https://doi.org/10.4000/ideas.12007

Este documento foi criado de forma automática no dia 16 novembro 2021.

\section{c) (i)}

IdeAs - Idées d'Amériques est mis à disposition selon les termes de la licence Creative Commons Attribution - Pas d'Utilisation Commerciale - Pas de Modification 4.0 International. 


\title{
Fronteiras nas Américas - Integração, segurança e migrações: abordagens críticas
}

\author{
Pierre-Alexandre Beylier, Anne-Laure Amilhat-Szary, Gregory Benedetti e
} Éric Tabuteau

Tradução : Isabel Moraes

\section{Fronteira-laboratório}

1 As Américas constituem um laboratório precioso para o estudo das fronteiras e suas evoluções. Não apenas isso. Ao longo da última década do "mundo sem fronteiras", o continente americano multiplicou seus projetos de integração regional, especialmente com o MERCOSUL e o ALENA, que testemunharam uma aproximação entre os países e a redução de suas barreiras alfandegárias. Por outro lado, há alguns anos essas mesmas fronteiras tornaram-se pontos de tensão em decorrência de uma série de problemas que se amplificaram - seja no que diz respeito aos tráficos de todos os tipos ou às tensões territoriais. Essas evoluções recentes nos levaram a propor uma leitura crítica dos processos fronteiriços que percorrem as Américas para melhor caracterizá-los, tanto em suas especificidades continentais como na maneira com a qual esse conjunto torna as grandes tendências mundiais legíveis. Em um contexto global de ascensão da teoria dos estudos fronteiriços, pode ser interessante nos interrogarmos sobre como uma abordagem continental permite avaliar as especificidades regionais, mas também contribuir, de maneira original, com esse esforço epistemológico (Mezzadra S. e B. Neilson, 2013), (Nail, 2016), (Parker et al, 2012), (Wastl-Walter, 2012).

Esta edição da revista IdeAs pretende abordar a temática das fronteiras sob o prisma de duas dinâmicas, a priori, antitéticas: a segurança e a integração, assim como seus impactos sobre as migrações. Na realidade, inseridas em processos contraditórios de "desmontagem e construção" (Machado De Olivera, 2009: 19), essas dinâmicas não somente estruturam as fronteiras, reticulares e lineares, servindo para filtrar o fluxo da 
mundialização (Amilhat-Szary A.L., 2015), mas também se chocam, o que, in fine, acaba por reforçar a ambivalência da instituição fronteiriça.

Teatro para o apetite colonial dos poderes europeus, o continente americano esteve sob suas influências por cerca de quatro séculos, desde sua (re)descoberta em 1492 até a sua descolonização na primeira metade do século XIX. Do estabelecimento de zonas de influência à criação de verdadeiros impérios coloniais, as Américas foram transformadas em uma extensão do Velho Mundo e fonte inesgotável de recursos peça central para a economia-mundo que começava a se desenvolver. Desde as colonizações, elas se constituem um espaço no qual o Ocidente reinventa constantemente as modalidades de seu leadership global [Rouquié A., 1987].

4 Assim, as Américas têm em comum o fato de suas fronteiras terem sido estabelecidas para "ordenar" o continente (Popescu G., 2011), antes mesmo da criação dos Estadosnações. Mais precisamente, essas fronteiras combinam de maneira original duas formas de apropriação territorial: de uma parte, uma lógica de conquista "zonal colonizadora" (frontier), que busca valorizar um ambiente considerado selvagem (wilderness) - lógica teorizada por Frédérick Turner em relação aos Estados Unidos (Turner F., 1964) - e de outra, uma vontade de entrelaçar o mundo em uma perspectiva ocidental do espaço (boundary) (Perrier Bruslé L., 2007).

5 Essa lógica dupla de conquista se deu às custas das populações ameríndias que povoavam o continente. Os poderes coloniais, depois os Estados recém-independentes, serviram-se das fronteiras - sistema de organização do espaço que era estranho às populações autóctones - para assujeitá-las e dominá-las, limitando suas mobilidades, atribuindo residência em reservas ou em certos países, ou impondo uma identidade "nacional" que não era a dessas populações. Logo, a "violência" fronteiriça (Jones R, 2017) não é uma novidade e, no que diz respeito às Américas, o seu caráter sobreposto $\mathrm{e}$ exógeno, que alguns veem como antecedentes, ancora essa violência na própria história do continente, gerando questões em termos de legitimidade e identidade.

6 Além dessas características históricas que lhe são próprias, as fronteiras americanas compartilham traços em comum com as fronteiras do resto do mundo. Em um contexto maior, marcado pelo desenvolvimento da mundialização e pela repercussão dos atentados de 11 de setembro de 2001, elas enfrentam fenômenos antitéticos a priori, mas concomitantes, de debordering e rebordering(Herzog L. et C. Sohn, 2019): por um lado, elas se apagam, se desfuncionalizam para facilitar a passagem dos fluxos comerciais e financeiros e, por outro, se reafirmam para controlar todos os tipos de mobilidade e estigmatizar certos tipos de migração. Isso é característico de um fenômeno que diferencia as modalidades de atravessamento de uma mesma fronteira em função de uma combinação de critérios que se individualizam e definem as "fronteiras" ou "borderities" díspares (Amilhat Szary, A.-L. e F. Giraut, 2015).

7 A sua aparente desfuncionalização (Eva F., 1996) alcançou outros patamares nos anos 1990, quando, abraçando as forças da mundialização, alguns países estabeleceram acordos comerciais - ALENA para a América do Norte e MERCOSUL para a América do Sul, e ainda o UNASUL na escala hemisférica. Com o objetivo de favorecer a integração regional, esses acordos propuseram uma visão particular da fronteira, considerada mais como uma "fonte" do que um "estigma" (Amilhat-Szary A.L., 2015: 85). A integração também foi vista como um "fator de estabilização" (Medina L., 2009: 41) no continente, com algumas regiões marcadas por frequentes conflitos territoriais desde o século XIX e onde algumas fronteiras são ainda hoje contestadas (Medina L., 2009: 36-37). 
8 No entanto, mesmo quando abertas às trocas e à economia de mercado, as fronteiras americanas viram algumas de suas atribuições se reforçarem simultaneamente. Depois dos atentados de 11 de setembro de 2001, a ameaça terrorista internacional levou os países do continente - com os Estados Unidos à frente - a repensarem o papel de seus limites internacionais. A fim de garantir a segurança dos territórios, as fronteiras tornaram-se o lugar de dispositivos de monitoramento e de controle high-tech, que podem convergir na construção de "muros", sintomas desse fenômeno de refronteirização e da violência associada. Fronteiras até então quase que desprotegidas - como aquela entre o Canadá e os Estados Unidos ou as díades latino-americanas testemunharam a implantação de uma série de novas medidas, que vão de drones a sensores terrestres, passando por torres equipadas com câmeras de visão noturna (Beylier P.A., 2016) . Se a luta contra o terrorismo domina os discursos, ela também parece ser utilizada como um pretexto para controlar as migrações que passam a ser o alvo explícito dessas medidas. A crise associada à COVID-19, que viu as fronteiras se fecharem sucessivamente, conferiu a esse fenômeno uma amplitude sem precedentes, e o texto de Nicolli Bernardes Ribeiro aborda essa perspectiva nas fronteiras brasileiras, nas quais a contradição entre o discurso nacionalista e o longo período de recusa ao fechamento das fronteiras em decorrência da pandemia se revela.

9 É, portanto, a partir dessa perspectiva continental que esta coleção trabalha a própria noção de fronteira, cuja definição problemática é a exposta a seguir. 0 artigo de Jean Clot sobre "as fronteiras porosas" ilustra a adaptação dos discursos a esse contexto em transformação. De maneira complementar, François-Michel Le Tourneau evidencia a "lógica reticular" dos garimpeiros em Guiana, que aproveitam a ausência de monitoramento dessas zonas fronteiriças remotas, o que vai na contramão da "lógica regional" dos Estados para os quais as fronteiras permanecem como ferramentas de soberania e de vigilância. Sejam contestadas, transgredidas, transcendidas, reforçadas ou integradas, as fronteiras estão no centro do debate político nas Américas. No debate público, elas parecem ter prevalecido sobre o discurso promovendo a integração continental no ALENA e seu sucessor ACEUM, assim como no MERCOSUL, e também em relação às duas Américas (UNASUL), organizações regionais que se apresentavam como modelos nos anos 1990.

10 Entretanto, o "trabalho da fronteira" (para traduzir a expressão inglesa border work) não é, nas Américas como em outros lugares, uma prerrogativa dos atores dominantes: ele é fruto de práticas "de baixo" (Rumford C., 2008) e os artigos destacam a maneira com a qual os habitantes das regiões fronteiriças interagem com as normas internacionais que encontram e desafiam, principalmente no que diz respeito ao garimpo na Guiana que parece se emancipar das normas, funcionando de forma "anacional", como ilustra o texto de F.-Michel Le Tourneau. A fronteira como uma "marca de identidade" (Piermay J.L., 2005: 206), evidencia o questionamento sobre o vínculo entre identidade, território e fronteira. A questão é ainda mais importante na medida em que, nesse continente, "o Estado precedeu a nação" (Medina L., 2009: 38). Portanto, o papel atribuído às fronteiras na "coesão nacional" (Ibid) revela-se ainda mais importante, visto que ele pode entrar em conflito com as representações das comunidades fronteiriças dentro das quais a interpretação que as populações autóctones fazem da construção de fronteiras pode desempenhar um papel essencial (Nates Cruz B., 2013). Nos textos aqui reunidos, as negociações e as confrontações entre populações regionais e móveis presentes nas regiões são frequentemente apresentadas 
em destaque, enquanto a questão migratória é compreendida como um problema central das zonas fronteiriças americanas na contemporaneidade.

\section{Segurança e migração nas fronteiras das Américas, dois termos necessariamente vinculados?}

11 Os atentados de 11 de setembro de 2001 - e em termos mais abrangentes, o surgimento de uma ameaça terrorista internacional, presente na América Latina desde os atentados em Buenos Aires, nos anos 1980 - modificaram o papel das fronteiras. A emergência de uma Fortress America (Alden E., 2008; Andreas P., 2003; Noble J., 2004) foi amplamente documentada em relação aos Estados Unidos, mas o fenômeno de rebordering pertence também às fronteiras latino-americanas. Nesse continente, também vemos uma política de reinterpretação original das grandes tendências da gestão de fronteiras na escala mundial como, por exemplo, a implementação de um aparato de segurança sem precedentes nas fronteiras brasileiras, sem um questionamento real sobre o crescimento dos fluxos de trocas internacionais, sejam legais ou ilegais (contrabando, narcotráfico etc.) (Dorfman A. et al, 2014; Dorfman A. et al, 2017).

$12 \mathrm{O}$ artigo de Beatriz Zepeda sobre o trabalho dos oficiais de segurança na fronteira Guatemalteca-Mexicana ou o texto de Cléa Fortuné sobre a interpretação da segurança feita pela comunidade transfronteiriça de Douglas (Arizona)/Agua Prieta (Sonora) conferem uma visão plena de nuances sobre o trabalho humano e as negociações que, no cotidiano, constroem o grande paradigma da "segurança". Assim, nosso interesse se volta aos aspectos materiais de tal dinâmica e à forma com a qual esse processo se territorializa. As abordagens históricas que renovam a questão do conflito na fronteira territorializada e multiplicam as dimensões da leitura permitem, nesse contexto, fazer com que as narrativas nacionais e nacionalistas evoluam.

13 As diferentes políticas implementadas a partir dos anos 2000 nas Américas fornecem uma ilustração particular do fenômeno de rebordering que está em jogo na dimensão mundial. Os artigos aqui reunidos abordam tanto os dispositivos e suas implicações para as relações fronteiriças, em uma abordagem comparativa (ver os artigos de Jean Clot e Laurence Cros) que permite evidenciar não apenas as dinâmicas que atravessam a América do Norte, mas também ligar as duas metades das Américas. (Brunet-Jailly E., 2007 ; Konrad V. et al, 2008).

Apesar dos fenômenos em comum que as estruturam, as fronteiras americanas veiculam uma certa especificidade; uma vez que seus papéis mudam de um país para o outro, ou de uma região para outra (Machado Oliveira T. C., 2009: 20): elas são marcadas, ao contrário, por uma "imensa variedade", especialmente na América Latina onde elas são mais numerosas. Entre as "fronteiras distantes" que separam as regiões marginais dos territórios e que "viram as costas para as fronteiras" (Argentina/Chile, Paraguai/Brasil...), as "fronteiras caprichosas", caracterizadas por vínculos transfronteiriços ilegais, principalmente em zonas urbanas de renovação (Costa Rica/ Nicarágua, México/Guatemala), ou ainda "as fronteiras vibrantes", que extraem seu dinamismo de uma população densa e inúmeras vantagens comparativas (Brasil/ Uruguai, Peru/Equador, México/Estados Unidos), sem esquecer as "fronteiras protocolares", regiões instrumentalizadas pelo poder central para promover "dinamismo" ou ainda lutar contra os tráficos ilegais de acordo com uma abordagem 
top-down (Chile/Argentina, Haiti/República Dominicana), vemos que os tipos de fronteiras são numerosos (Machado de Oliveira T.C., 2009: 28-30). Diferentes níveis de cooperação transfronteiriça se estabelecem, resultando em um crescimento de força das chamadas relações interterritoriais paradiplomáticas (Gonzalez Miranda, S. et al., 2016).

As travessias das fronteiras e seu crescente custo humano aparecem, atualmente, como elementos essenciais para a compreensão das fronteiras americanas (De Leon J. e M. Wells, 2015). De maneira impressionante, diferentes artigos desta edição (os de MarieLaure Coubès e de Jean Clot) demonstram como a passagem da linha não pode mais ser compreendida de forma multiescalar. Na verdade, é preciso analisar tanto os fluxos intercontinentais, ligados principalmente às mobilidades do trabalho, mas também a forma com a qual as Américas se inserem em estratégias migratórias de grande amplitude, com uma quantidade cada vez mais numerosa de pessoas que, por exemplo, procuram chegar à América do Norte saindo da Africa, atravessando o Atlântico pela antiga rota dos escravizados e depois tentando a sorte em longos e perigosos trajetos rumo ao norte. Isso reforça questões ligadas à vulnerabilidade e aos riscos, assim como as estratégias implementadas pelas comunidades fronteiriças para conviver com a insegurança (ver o texto de Clea Fortuné) e interpretar à sua maneira as injunções internacionais. Os fenômenos ilegais que se desenvolveram nas Américas (o narcotráfico, a imigração ilegal, os cartéis etc.) não podem ser abordados sem que suas causas, ramificações, implicações para as populações locais, assim como as políticas adotadas para combatê-los, sejam examinadas. Eles não devem fazer com que esqueçamos as múltiplas maneiras com as quais as populações lidam com as fronteiras no cotidiano, especialmente em relação à educação e saúde.

16 Finalmente, visto que os espaços fronteiriços são lugares em constante evolução em que a expressão estética e os imaginários são rapidamente recompostos (Rodney L., 2017; Amilhat-Szary A.-L., 2014), a mediação artística do imaginário em torno da linha aparece como um ponto de entrada essencial para a compreensão da atual evolução das fronteiras americanas. $\mathrm{O}$ texto de Marion Gautreau, dedicado à abordagem fotográfica da fronteira México/Estados Unidos, analisada retrospectivamente a partir de mais de quarenta anos por meio do trabalho de Elsa Medina e de Francisco Mata Rosa, responde a esta busca.

\section{A lógica da organização da edição}

Os artigos aqui apresentados desdobram-se em três maneiras complementares em torno de uma problemática em comum. Três deles trabalham a definição de segurança para mostrar, por um lado, seu aspecto multifacetado e multiescalar, e a importância da interpretação dos atores locais em relação às questões globais. Eles correspondem ao artigo de Beatriz Zepeda, intitulado "La sécurité à la frontière entre le Mexique et le Guatemala. Comprendre les risques et les menaces du point de vue des responsables de la sécurité mexicains et guatémaltèques" (em português: "A segurança na fronteira entre o México e a Guatemala. Compreender os riscos e as ameaças sob o ponto de vista dos responsáveis mexicanos e guatemaltecos pela segurança"), ao texto de François-Michel Le Tourneau, "La frontière?Quelle frontière? La dynamique transnationale de l'orpaillage clandestin en Guyane française (em portugues: "A fronteira? Qual fronteira? A dinâmica transnacional do garimpo clandestino na Guiana francesa"), bem como ao de Nicolli 
Bernardes Ribeiro, "Contingence pandémique et impacts migratoires : une analyse des actes normatifs pour fermer la frontière entre le Brésil et le Venezuela" (em português: "Contingência pandêmica e impactos migratórios: uma análise dos atos normativos para o fechamento da fronteira entre o Brasil e a Venezuela").

Uma segunda série de textos se interessa pela questão migratória para se interrogar sobre sua complexa ligação com os problemas de segurança. Ela é formada pelos artigos de Marie-Laure Coubès, "De travailleurs mexicains sans-papier à familles centraméricaines demandeuses d'asile : la transformation des flux migratoires à la frontière Mexique-États-Unis, 2005-2020" (em português: "Dos trabalhadores mexicanos sem documentos às famílias centroamericanas solicitantes de asilo: a transformação dos fluxos migratórios na fronteira México-Estados-Unidos (2005-2020)), de Laurence Cros, "Demandes d'asile à la frontière américano-canadienne : l'Entente entre le Canada et les États-Unis sur les tiers pays sûrs et les valeurs canadiennes " (em português: "Pedidos de asilo na fronteira américanocanadense: o acordo entre Canadá e Estados Unidos a respeito dos terceiros países seguros e os valores canadenses") e pelo de Jean Clot sobre "La frontière entre le Mexique et le Guatemala: une frontière 'poreuse' ?" (em português: "A fronteira entre México e Guatemala: uma fronteira 'porosa'?").

O último grupo de artigos matiza de maneira estimulante esta oposição frequentemente caricatural entre segurança e migração, mostrando como ela é negociada no cotidiano por práticas que renovam os termos. Isso é o que mostra Cléa Fortuné de maneira global na escala de uma aglomeração em "(In)sécurité dans les villes frontalières ? Étude de Douglas (Arizona) et Agua Prieta (Sonora)" (em português: “(In)segurança nas cidades fronteiriças? Estudo sobre Douglas (Arizona) e Agua Prieta (Sonora)"), aparecendo também nos usos escolares no texto de Isabelle Sinic, "Coopération Etats-Unis/Mexique: Quelles perspectives pour l'éducation des élèves transnationaux? La scolarisation des mineurs binationaux : une nouvelle forme de coopération transfrontalière" (em português: "Cooperação Estados Unidos/México: quais perspectivas para a educação dos alunos transnacionais? A escolarização de menores binacionais: uma nova forma de cooperação transfronteiriça") ou nos usos medicais na fronteira no trabalho de Elisabeth Fauquert, "Patients sans frontières : les déterminants socio-économiques du tourisme médical aux États-Unis" (em português: "Pacientes sem fronteiras: os determinantes socioeconômicos do turismo medical nos Estados Unidos"). E finalmente em "Regards sur la ligne. La frontière Mexique - États-Unis à travers l'objectif d'Elsa Medina et de Francisco Mata Rosas" (em português: "Olhares sobre a linha. A fronteira México - Estados-Unidos pela ótica de Elsa Medina e de Francisco Mata Rosas"), em que Marion Gautreau nos oferece um texto cuja abordagem histórica confirma as análises contemporâneas e cuja dimensão artística as amplia.

\section{Aberturas}

Além da perspectiva geral proposta pela coleção de artigos recolhidos nesta edição, alguns temas restam a ser aprofundados para compreendermos mais adequadamente a evolução das fronteiras americanas. A questão das fronteiras marítimas cuja delimitação gera grandes tensões, principalmente na América Central (Medina L., 2009: 40 e Medina L., 2021), precisaria ser mais bem documentada no continente. Ela abre a reflexão sobre as fronteiras externas do continente, especialmente sobre a frente ártica (Nicol H. et al, 2009). Por fim, ela questiona, de forma mais genérica, a dimensão 
ambiental das questões ligadas às fronteiras (Guyot S., 2011; Wadewitz L., 2012), que toma uma dimensão singular nas Américas onde, para uma maioria, os limites internacionais atravessam zonas de baixa densidade populacional.

É preciso ressaltar que o continente americano permanece marcado por uma miríade de fronteiras para além das geopolíticas: sociais e raciais, principalmente. A questão específica das fronteiras urbanas (Chevalier J. et al, 2004) nos espaços continentais que compartilham da mesma experiência de desenvolvimento ligado ao neoliberalismo econômico levanta diversas interrogações sobre suas segmentações. Abordagens interseccionais restam a ser construídas para continuar a explorar a multidimensionalidade dos processos fronteiriços nas Américas.

\section{BIBLIOGRAFIA}

Alden, Edward, The Closing of the American Border, New York City, Harper and Collins, 2008.

Andreas, Peter et Thomas J. Biersteker, The Rebordering of North America: Integration and Exclusion in a New Security Context, New York, Routledge, 2003.

Amilhat-Szary, Anne-Laure. 2014. « Latin American Borders on the Lookout: Recreating borders through art in the Mercosul ». P. 346-78 in Making the Border in Everyday Life, édité par R. Jones et C. Jonhson. Farnham, Ashgate.XAmilhat Szary, Anne-Laure, Qu'est-ce qu'une frontière aujourd'hui ? 3e tirage. Paris, PUF, 2015.

Amilhat Szary, Anne Laure, et Frédéric Giraut (dir.), Borderities: The Politics of Contemporary Mobile Borders, Basingstoke, Palgrave Macmillan, 2015.

Beylier, Pierre-Alexandre, Canada-États-Unis, les enjeux d'une frontière, Rennes, Presses universitaires de Rennes, Des Amériques, 2016

Brunet-Jailly, Emmanuel (dir.), Borderlands: Comparing Border Security in North America and Europe, Ottawa, University of Ottawa Press, 2007.

Chevalier, Jacques et Cristina Carballo, « Fermetures résidentielles et quête de l'entre-soi, entre Nord et Sud Des Amériques », L'espace Géographique, vol. 33, n² 4, 2004, p. 325-335.

De Leon, Jason, et Michael Wells, The Land of Open Graves, Los Angeles, University of California Press, 2015.

Dorfman Adriana, et Daniel Francisco de Bem, « Contrabando, Tragédia e Reflexividade: Antígona Na Fronteira Gaúcha », in Revista Do Centro de Educação e Letras, n¹5, 2014, p. 33-51.

Dorfman, Adriana et al., « Political Commodities and Sovereignty Management: Cigarette Smuggling across Brazil's Southern Borders ", in Geopolitics, vol.22, n 4, 2017, p. 863-886 $<$ https://doi.org/10.1080/14650045.2017.1356288>.

Eva, Fabrizio, 1996, «International Boundaries, Geopolitics and the (Post)Modern Territorial Discourse: The Functional Fiction ». in Newman, David (dir.), Boundaries, Territory and Postmodernity, London, Taylor \& Francis, p. 32-51. 
Gonzalez Miranda, Sergio, et al. (dir.), Relaciones transfronterizas y paradiplomacia en América Latina. Aspectos teóricos y estudio de casos, Santiago de Chile, RIL editores, 2016.

Guyot, Sylvain, « The Eco-Frontier Paradigm: Rethinking the Links between Space, Nature and Politics » in Geopolitics n¹6(3), 2011, p.675-706.

Herzog, Lawrence A., et Christophe Sohn, « The Co-Mingling of Bordering Dynamics in the San Diego-Tijuana Cross-Border Metropolis » in Territory, Politics, Governance 7 (2): 2019, p. 177-99, https://doi.org/10.1080/21622671.2017.1323003.

Jones, Reece, Violent Borders: Refugees and the Right to Move, London/ New York, Verso, 2017.

Konrad, Victor, et Heather Nicol, Beyond Walls: Re-Inventing the Canada-United States Borderlands, London, Ashgate, 2008.

Machado de Oliveira, Tito Carlos, «Frontières en Amérique latine : réflexions méthodologiques ", Espaces et sociétés, vol. 138, no. 3, 2009, pp. 19-33.

Medina, Lucile, «Les frontières de l'isthme centraméricain, de marges symboliques à des espaces en construction ", in Espaces et sociétés vol. 138, no. 3, 2009, p. 35-50.

Medina, Lucile, « Pouvoir, préservation, prédation. Les frontières d'Amérique latine témoins d'un continent sous tensions » in L'Espace Politique. Revue en ligne de géographie politique et de géopolitique, $\mathrm{n}^{\circ} 42$, 2021, doi: 10.4000/espacepolitique.9424.

Mezzadra, Sandro, et Brett Neilson, Border As Method, or, the Multiplication of Labor, Durham, NC, Duke University Press, 2013.

Nail, Thomas, Theory of the Border, Oxford/ New York, Oxford University Press, 2016.

Nates Cruz, Beatriz (dir.), La Frontera, Las Fronteras. Diálogos Transversales En Estudios Territoriales Contemporáneo, Editorial Universitaria de Caldas, 2013.

Nicol, Heather et Lassi Heininen, « Networking the North: Cross Border Connections and the New International Circumpolar Geopolitics » in Southern Journal of Canadian Studies, vol. 2009/2, 2009, p. 11-26.

Noble, John, « Fortress America or Fortress North America? », paper prepared for the IRPP on North American Integration: Migration, Trade and Security, April 2004.

Parker, Noel et Nick Vaughan-Williams, « Critical Border Studies: Broadening and Deepening the "Lines in the Sand" Agenda » in Geopolitics, vol. 17, 2012, p.727-33.

Perrier-Bruslé, Laetitia, « The Front and the Line: The Paradox of South American Frontiers Applied to the Bolivian Case » in Geopolitics, vol.12, 2007, p. 57-77.

Piermay, Jean-Luc, «La Frontière et ses ressources : regards croisés » in Antheaume, Benoît et Frédéric Giraut (dir.) Le territoire est mort : vive les territoires ! : une refabrication au nom du développement, Montpellier, IRD Editions, 2005, p. 2013-221.

Popescu, Gabriel, Bordering and Ordering the Twenty-first Century: Understanding Borders, Plymouth, Rowman and Littlefield Publishers Inc., 2011.

Rensink, Brenden, Native but Foreign, Indigenous Immigrants and Refugees in the North American Borderlands, College Station, TX, Texas A\&M University Press, 2018.

Rodney, Lee, Looking beyond Borderlines: North America's Frontier Imagination, New York, Routledge, Taylor \& Francis Group, Routledge Advances in Art and Visual Studies \#19, 2017.

Rouquié, Alain, Amérique latine : introduction à l'Extrême-Occident, Paris, Seuil, 1987. 
Rumford, Chris (dir.), Citizens and Borderwork in Contemporary Europe, New York/ London, Routledge, 2008.

Turner, Frederick. J., La Frontière dans l'histoire des États-Unis, Paris, Presses universitaires de France, 1963 [1893].

Wadewitz Lissa K., The Nature of Borders. Salmon, Boundaries, and Bandits on the Salish Sea, Bellingham, University of Washington Press, 2012.

Wastl-Walter, Doris (dir.), Companion to Border Studies, Farnham, Ashgate, 2012.

\section{AUTORES}

\section{PIERRE-ALEXANDRE BEYLIER}

Pierre-Alexandre Beylier est actuellement maître de conférences en études nord-américaines à l'université Grenoble-Alpes. Ancien élève de l'Ecole Normale Supérieure de Cachan et Agrégé d'anglais, il a effectué une thèse à l'Université Paris 3-Sorbonne Nouvelle, portant sur les mutations qu'a connues la frontière Canada/Etats-Unis depuis le 11 septembre 2001. Il a publié aux Presses Universitaires de Rennes un ouvrage sur ce sujet : Canada/Etats-Unis : les enjeux d'une frontière. Il s'intéresse désormais aux questions relatives aux communautés frontalières et aux villes-frontière.

\section{ANNE-LAURE AMILHAT-SZARY}

Anne-Laure Amilhat Szary est professeure à l'Université Grenoble-Alpes. Ancienne élève de l'ENS Fontenay, agrégée de Géographie et membre honoraire de l'IUF, c'est une géographe politique qui analyse les frontières. Elle développe des recherches concernent les interrelations entre espace et art dans les lieux contestés et construit un musée imaginaire du border art. Cofondatrice du collectif antiAtlas des frontières (http://www.antiatlas.net/), elle anime le Performance Lab dédié à la Recherche-Création.

Auteure de : Après les frontières, avec la frontière (2006, avec M.-C. Fourny), Qu'est-ce qu'une frontière aujourd'hui ? (2015), Borderities, the Politics of Mobile Borders (2015, avec F. Giraut), Histoires de frontières, une enquête sud-africaine (2017, collectif), Géopolitique des frontières. Découper la terre, inventer une vision du monde (2020), Frontières (2020, avec G. Hamez)

\section{GREGORY BENEDETTI}

Gregory Benedetti, agrégé d'anglais et docteur en civilisation américaine, est maître de conférences à l'Université Grenoble Alpes, et membre de l'Institut des langues et des cultures d'Europe, Amérique, Afrique, Asie et Australie. Ses recherches portent essentiellement sur la question raciale aux États-Unis, et plus particulièrement sur la communauté afro-américaine, tant sur le plan politique que culturel. Ses premières publications s'intéressaient notamment à la nouvelle génération d'hommes politiques noirs, dont Barack Obama est devenue la figure tutélaire, mais non exclusive, en devenant président des États-Unis en 2008. Ses travaux s'intéressent également à l'histoire et la politique afro-américaine dans son ensemble, ainsi qu'à la représentation de la communauté noire dans les productions culturelles comme les séries télévisées. Il a dernièrement travaillé sur les élections présidentielles américaines en coorganisant une journée d'études à l'Université Grenoble Alpes. Il est membre de l'Association française d'études américaines depuis 2008. 


\section{ÉRIC TABUTEAU}

Professeur des Universités, Université d'Orléans.

UFR des lettres, langues et arts. 